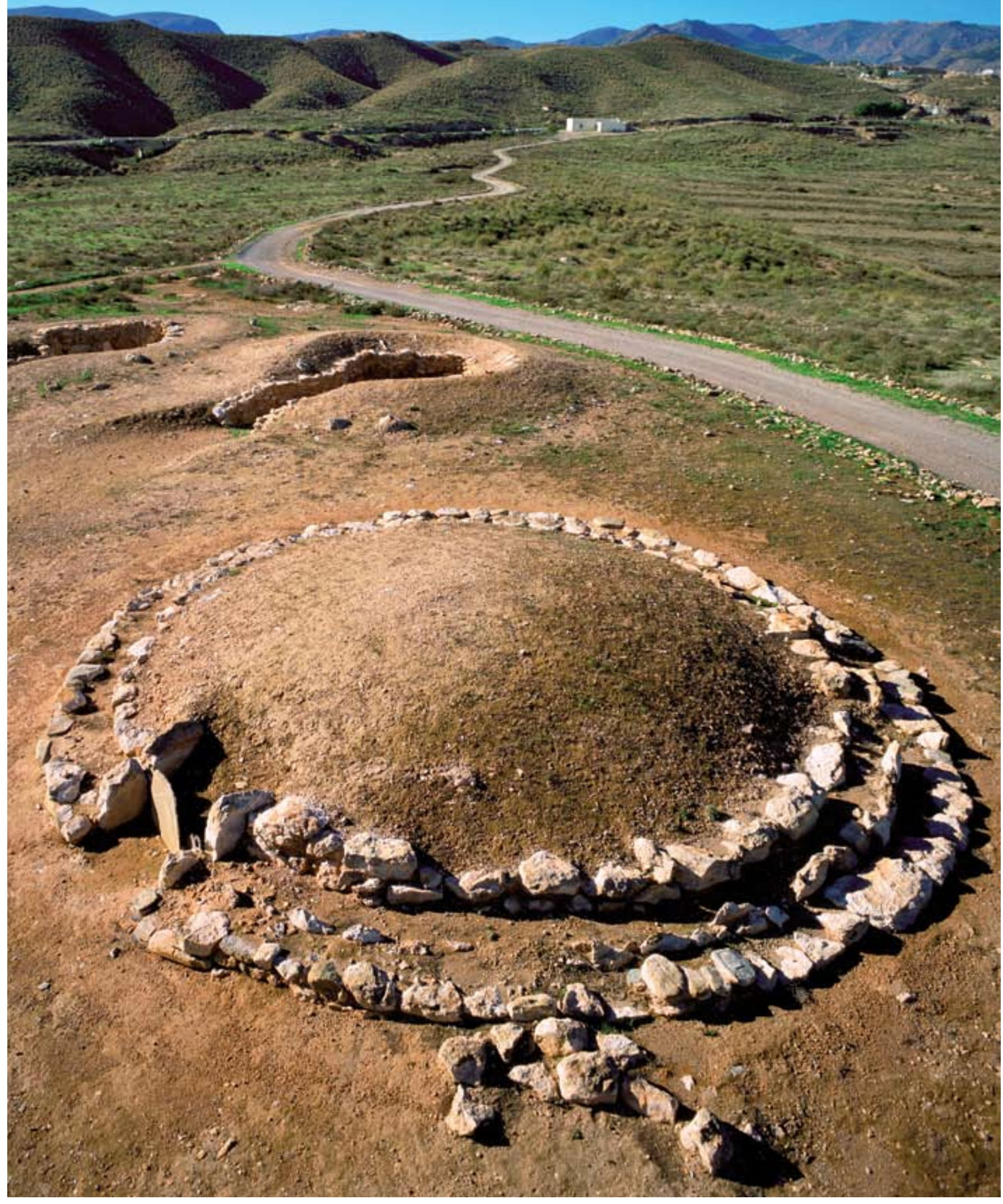

Sepulturas de cámara circular de Los Millares. Foto: Miguel Ángel Blanco de la Rubia. Fuente: Consejería de Cultura de la Junta de Andalucía 


\section{Los Millares y su dominio sobre el valle del Andarax}

Fernando Molina González, Juan Antonio Cámara Serrano, Dpto. de Prehistoria y Arqueología, Universidad de Granada
El medio ambiente del sureste, actualmente árido, ha sido considerado por diversos autores como un elemento determinante en el desarrollo de las sociedades de esta región entre el Neolítico Reciente y el Calcolítico al obligar a una serie de cambios tecnológicos y sociales destinados a facilitar el asentamiento humano. Además, a la hora de valorar los condicionantes del medio sobre las actividades humanas, y especialmente sobre las actividades agropecuarias, también se ha planteado la escasez de tierra arable en esta región, dada la extensión de áreas de fuerte pendiente. En cualquier caso tanto la pérdida de suelo en áreas elevadas como la disminución de las precipitaciones, y sobre todo de la humedad, son fenómenos relativamente recientes unidos a la deforestación, y aunque las oscilaciones climáticas han existido en el pasado no se puede trasladar a la Prehistoria Reciente un ambiente árido similar al actual.

Los análisis paleoambientales realizados a partir del proyecto Millares han demostrado un ambiente más húmedo que el actual, aunque a partir del 4000 a. de C. se tiende a una disminución de las precipitaciones, con una mejora relativa entre el 3300 y el 2200 a. de C. Durante todo este tiempo el valle del Andarax ofrecía un paisaje de tipo mediterráneo con mayor cobertura vegetal en las zonas más elevadas, donde el pinar sustituía a las encinas, y con bosques-galeria de especies caducifolias en torno a los cursos de agua, algunos de los cuales, como el Andarax, debieron ser permanentes y junto a los que vivian animales como las nutrias, galápagos, ratas de agua y diversas anátidas, como el ánade real y el ánsar careto (PETERS; DRIESCH, 1990; RODRÍGUEZ; VERNET, 1991; ARAUS et ál., 1997).

Entre el VI y el V milenio a. de C., durante el Neolítico, la movilidad estacional de las comunidades humanas configura en el Andarax pequeños asentamientos con una densidad baja de restos, habitados episódica y periódicamente, junto con la ocupación de algunas cuevas, que por mucho tiempo se han considerado características y exclusivas del periodo. Estos yacimientos al aire libre se suelen situar en áreas altas desde las que controlaban visualmente su territorio de explotación, como es el caso del al- jibe de Lubrin (Tabernas) (ALCARAZ et ál., 1994). Poco a poco, el aumento de la estabilidad acentuó la necesidad de remarcar la propiedad de las diferentes partes del territorio de explotación, utilizándose para ello las tumbas megalíticas desde la transición al IV milenio a. de C. Se trata de sepulcros bajo túmulo de cámara circular o poligonal sin corredor de acceso, destinados al enterramiento de pocos individuos.

A partir del IV milenio a. de C. la población se sedentariza como resultado de la consolidación de la economía agropecuaria y la restricción de la movilidad, a excepción de pequeños grupos humanos que acompañaban estacionalmente los rebaños. Se construyen las primeras aldeas situadas en áreas favorables, de transición entre ecosistemas, con fácil acceso al agua y que permiten, todavía, un control del entorno, aspectos que ejemplifica en el Andarax el asentamiento del cerro de la Chinchilla en Rioja y, sobre todo, determinados yacimientos del pasillo de Tabernas, junto al arroyo de los Molinos y sus afluentes. Las causas de este proceso se deben buscar en la necesidad de mano de obra para las labores agrarias (especialmente en los momentos de la cosecha), la competencia con otras comunidades y la vinculación interpersonal resultado de los primeros procesos de acumulación de riqueza (pecuaria).

El yacimiento de Los Millares se funda hacia el 3300 a. de C. (M0LINA; CÁMARA, 2005), cuando los procesos de diferenciación entre asentamientos estaban ya marcándose, lo que puede explicar sus excepcionales características. Ya desde su inicio presenta tres líneas concéntricas de muralla, que cierran las dos mesetas más internas de un espolón situado en la confluencia de la Rambla de Huéchar con el río Andarax, junto a la cual la muralla más interna configura una ciudadela en la que una gran cisterna, a la que llegaba un largo acueducto (SIRET, 1893), ayudaba a mantener constante el suministro hídrico para personas y animales.

Desde su fundación, el poblado estaría acompañado por una amplia necrópolis de sepulcros tumulares (SIRET, 1893; LEISNER; LEISNER, 1943; ALMAGRO; ARRIBAS, 1963), que se extendia por la meseta más externa, amplia y elevada del espolón, actuando 

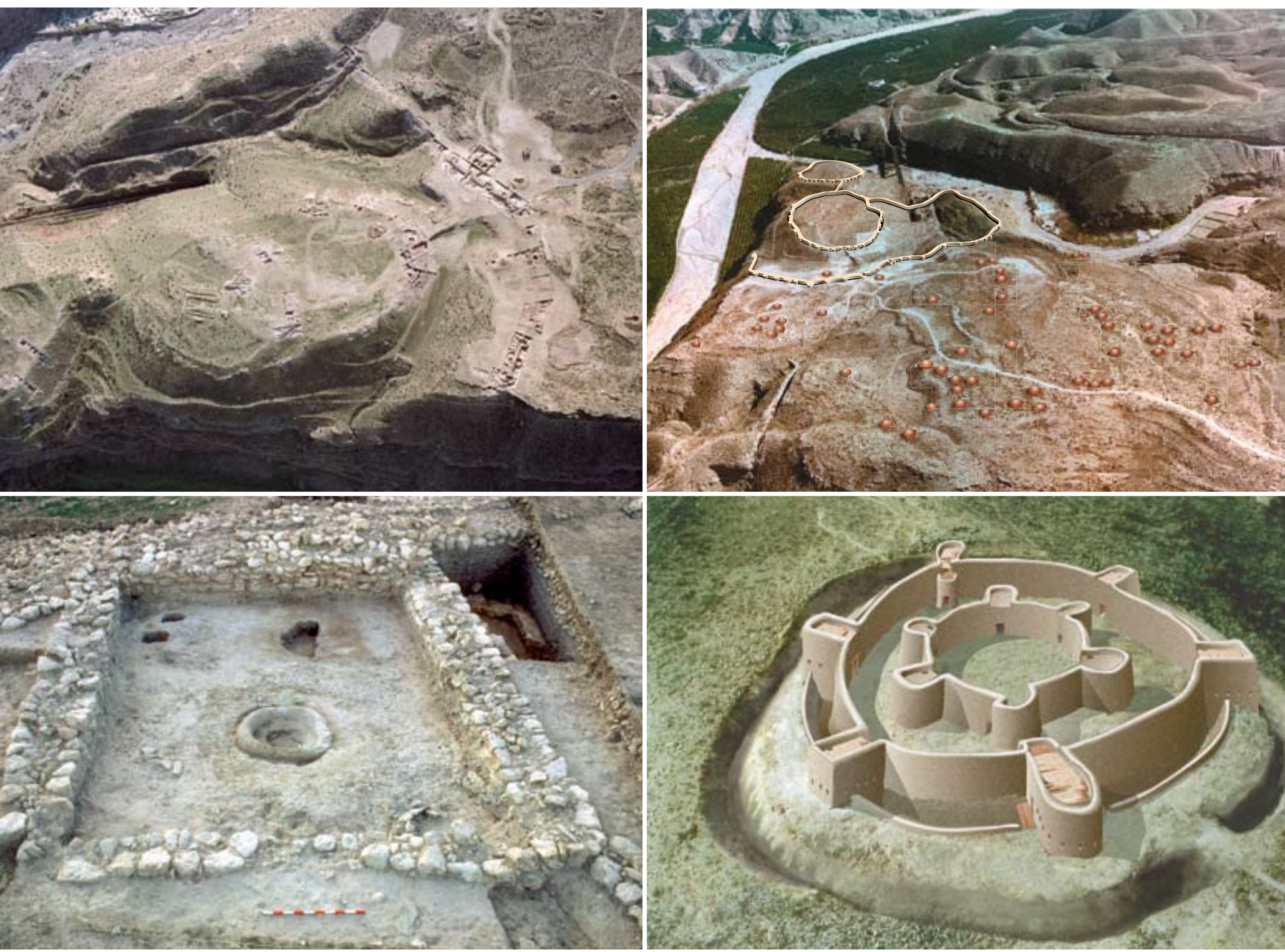

Vista aérea del poblado de Los Millares. Fuente: Paisajes Españoles Taller metalúrgico de Los Millares. Fuente: Dpto. de Prehistoria, Universidad de Granada

Los Milllares con la reconstrucción de las líneas de fortificación y la necrópolis. Infografía: M. Salvatierra

Reconstrucción del Fortín 1 de Los Millares. Infografía: A. Luque

como una línea de defensa ritual exterior. La necrópolis está compuesta fundamentalmente por tumbas que presentan corredor de acceso, segmentado por puertas abiertas en las losas de piedra, y cámara circular de mampostería con zócalos revestidos por lajas de pizarra, cubierta con falsa cúpula (tholoi) o con techumbre plana de materia orgánica. En el pasillo o en la cámara pueden abrirse pequeños nichos laterales para los enterramientos infantiles. El conjunto se cubre con túmulos de tierra y piedras. Al exterior las tumbas poseen un pequeño vestíbulo destinado a la celebración de rituales funerarios. Todos los sepulcros son de uso colectivo y en ellos se llegaron a enterrar un máximo de unos 100 individuos con sus ajuares funerarios. Junto a las tumbas de cámara circular existen 3 tumbas dolménicas que ofrecen técnicas constructivas y ajuares funerarios similares a los de las cercanas agrupaciones megalíticas del piedemonte de la sierra de Gádor.

Hacia el 2800 a. de C. el agregado urbano de Los Millares acrecienta su importancia con la ocupación de parte de la meseta exterior, defendida por una nueva muralla más externa, acompañada de foso, que conserva un perimetro de unos $400 \mathrm{~m}$ y que llega a integrar determinadas sepulturas en su recinto interior. Esta muralla posee una anchura de unos dos metros y presenta a intervalos regulares bastiones semicirculares y torres de planta oval, estando la entrada principal defendida por una gran barbacana.

Aunque las excavaciones en el poblado no han sido muy extensas se han podido documentar diferencias en las dimensiones de las viviendas (más pequeñas en la zona exterior), en los patrones de consumo (con cerdos adultos castrados y bóvidos jóvenes en la ciudadela) (NAVAS et ál., 2008) y en la existencia de edificios especiales (talleres metalúrgicos y gran construcción de planta rectangular situada al interior de la tercera muralla). Estas diferencias sociales ya habian sido sugeridas por el estudio de la necrópolis (CHAPMAN, 1991), donde las sepulturas muestran diferencias en dimensiones, complejidad estructural, emplazamiento y conteni- 

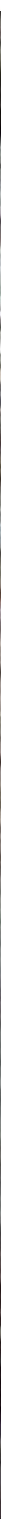

Barbacana de la puerta principal en la muralla exterior de Los Millares. Foto: Migue Angel Blanco de la Rubia. Fuente: Consejería de Cultura de la Junta de Andalucía

Vista aérea vertical de las excavaciones en el Fortín 1 de Los Millares. Fuente: Paisajes Españoles

do, hasta el punto de que las tumbas más ricas se situaban, dentro de cada una de las agrupaciones que se han definido dentro de la propia necrópolis, en la zona más cercana al asentamiento o al camino de acceso a éste (MOLINA; CÁMARA, 2005).

Al menos desde el 2600 a. de C. el sistema defensivo de Los Millares fue completado con dos series paralelas de 13 fortines de diversa complejidad a uno y otro lado de la Rambla de Huéchar (ARRIBAS et ál., 1987). En ellos las actividades domésticas (textiles, por ejemplo.) están ausentes y el almacenaje y procesado de productos alimentarios (grano y sal) supera, con mucho, las necesidades de los residentes. Además se ha determinado la realización de actividades artesanales (en especial la talla de puntas de flecha) que se han relacionado con actividades de iniciación de los jóvenes. Además la función militar queda claramente demostrada no sólo por el emplazamiento y la forma general de esos fortines, algunos como el Fortín 1 verdaderas fortalezas con doble recinto rodeado de fosos, sino por la documentación de saeteras que
Aunque las excavaciones en el poblado no han sido muy extensas, se han podido documentar diferencias en las dimensiones de las viviendas, en los patrones de consumo y en la existencia de edificios especiales 


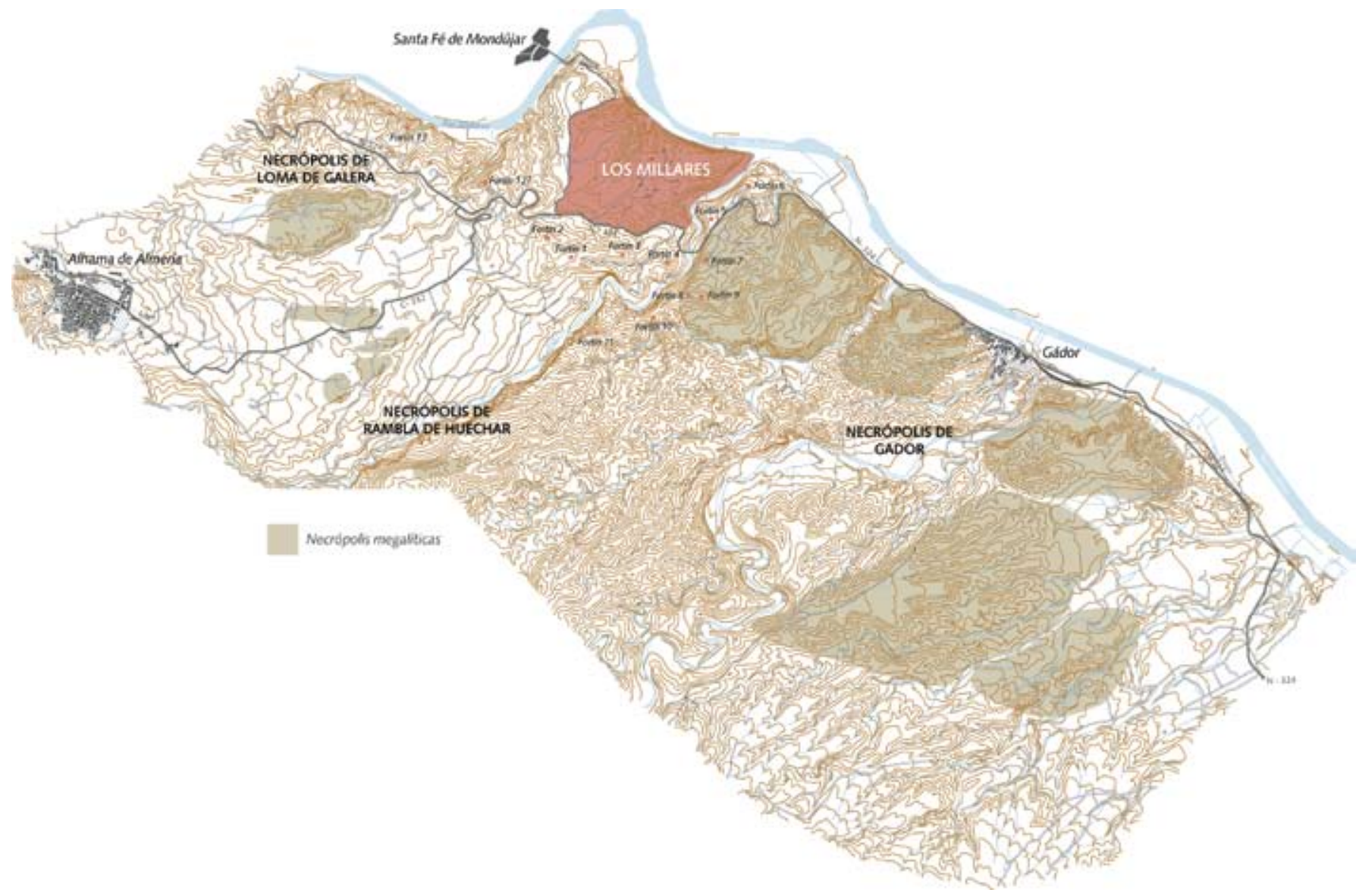

Los Millares y las agrupaciones megalíticas de su entorno. Mapa: Dpto. de Prehistoria, Universidad de Granada

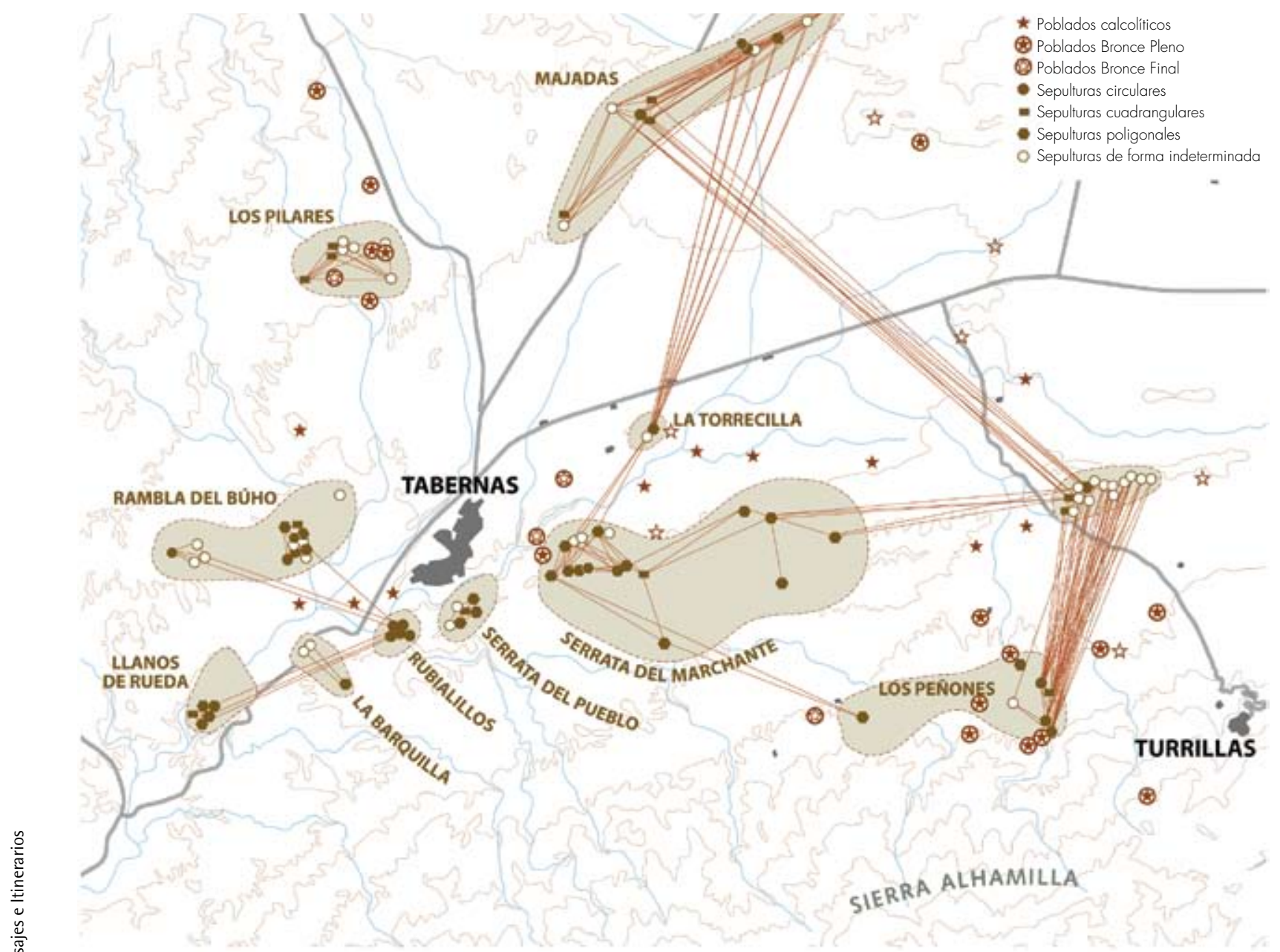

Distribución de yacimientos y visibilidad en el Pasillo de Tabernas durante la Prehistoria Reciente. Mapa: Dpto. de Prehistoria, Universidad de Granada 
atraviesan las paredes de murallas y bastiones cubriendo todos los puntos de acceso y que en el caso del recinto interior de esta fortaleza fueron inutilizadas cuando dejaron de ser funcionales al construirse un nuevo recinto exterior. Además la planificación no sólo incluyó el diseño general del sistema defensivo sino el esquema planimétrico de los fortines, manteniéndose incluso el mismo centro geométrico utilizado para diseñar la muralla exterior (ESQUIVEL; NAVAS, 2005). Los fortines, según las dataciones disponibles, fueron destruidos por un incendio coetáneo hacia el 2150 a. de C., momento en que posiblemente se abandone el asentamiento de Los Millares.

Los fortines ejercieron un fuerte control sobre las poblaciones del entorno de la Sierra de Gádor, presentes en pequeños poblados de piedemonte que, desde el IV Milenio a. de C., manifestaron su identidad a partir del enterramiento de sus muertos en necrópolis megalíticas que descendian hasta el valle del Andarax. Estas comunidades, como las del bajo Andarax, las del pasillo de Tabernas, la comarca de Gata-Nijar o el río NacimientoPasillo de Fiñana, quedaron integradas a lo largo del III milenio a. de C. en la unidad territorial controlada por Los Millares y adquirieron nuevos simbolos de identidad/pertenencia visibles en los sepulcros de falsa cúpula y en los ajuares funerarios contenidos en las necrópolis de Loma de Galera (Alhama), El Chuche (Pechina), Los Rubialillos (Tabernas), El Barranquete (Nijar) o Los Milanes (Abla).

Para comprender el control territorial del entorno inmediato de Los Millares debemos tener en cuenta también todo el poblamiento del área. Las tumbas enfatizaban el control de los valles, colocándose especialmente en los puntos en los que los cursos secundarios se incorporan a un río de mayor nivel. Este sistema permite marcar tanto las áreas susceptibles de ser explotadas, aun exiguas, como las rutas de desplazamiento a través de ellas, por las zonas llanas relativamente alejadas de los cursos fluviales. El sistema permite maximizar el uso de las construcciones e implica en primer lugar la anterioridad del control sacro (a partir de los megalitos) sobre el militar (fortines). En segundo lugar se aprecia la oposición entre el control más inmediato del territorio de Los Millares (con fortines) del más alejado (con tumbas). Finalmente se observa la similitud en las estrategias de ocupación del espacio, hasta el punto de que las concentraciones de tumbas resultan relativamente aisladas unas de otras (frente a lo que podemos ver en el Pasillo de Tabernas), con las necrópolis más amplias en los altiplanos explotables, donde diversas áreas cercadas inscritas en las necrópolis (CARA; RODRÍGUEZ, 1984) podrian hacer sospechar que se integrarian en el mismo lugar las tumbas, los rebaños y, tal vez, las viviendas.

Las prospecciones sistemáticas en el pasillo de Tabernas ofrecen sin duda los mejores datos para estudiar los límites de la influencia de Los Millares en los territorios algo más distantes de la cuenca del Andarax (CÁMARA; MOLINA, 2004). El sistema creado por la distribución de tumbas resulta mucho más com-

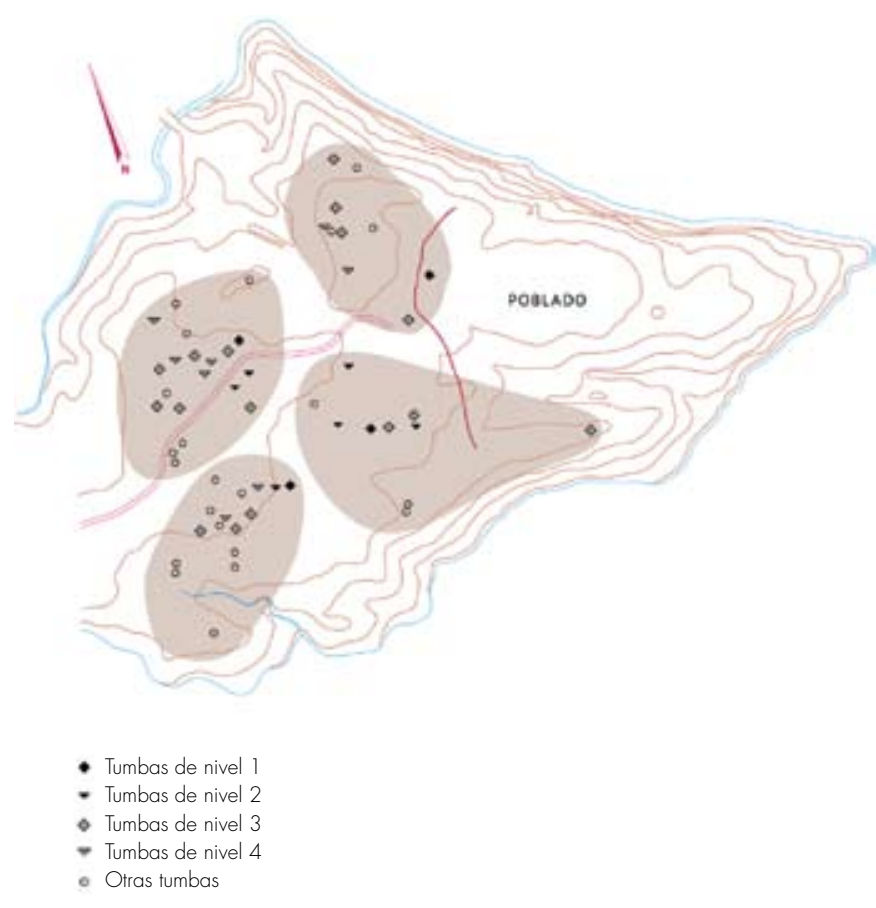

Necrópolis de Los Millares. Modelo de la agrupación y jerarquía de las tumbas. Mapa: Dpto. de Prehistoria, Universidad de Granada

plejo que el descrito para el bajo Andarax y supone, con su mejora por la continua adición de tumbas, la demarcación total de las rutas de desplazamiento no sólo desde el valle principal de Los Molinos hasta la sierra de los Filabres sino dentro de cada una de las cadenas montañosas perpendiculares a estos dos ejes (sierra de Velefique, hoya de la Matanza, Sierra Bermeja, etc.). Un importante elemento que nos puede indicar cómo en estas necrópolis dispersas la exhibición de la desigualdad quedaba unida a la demarcación de las rutas, es el hecho de que en cada agrupación de tumbas las que muestran mayor intervisibilidad están construidas siguiendo patrones formales diferentes (rectangulares donde dominan las tumbas poligonales o poligonales donde dominan las rectangulares) y, a menudo, son las únicas que muestran corredor.

La disposición de las tumbas y su intervisibilidad en cualquier caso implica la oposición entre dos unidades territoriales, una al este y otra al oeste, hasta el punto de que los poblados quedan situados detrás de la línea divisoria entre ambos conjuntos. Al oeste todos los asentamientos presentan dimensiones similares excepto Terrera Ventura, que podemos considerar como el principal asentamiento del Pasillo de Tabernas y es el único poblado de esta zona ligado a una necrópolis de tholoi, Los Rubialillos, con grandes cámaras circulares (GUSI, 1986). En el área oriental del Pasillo la concentración del poblamiento entre el Neolítico Reciente y el Calcolítico condujo al aumento de dimensiones de algunos poblados, la desaparición de otros y la preponderancia de El Marchalillo en la zona fronteriza y de Los Peñones en los accesos a Sierra Alhamilla. 